\author{
Jurnal E-KOMTEK (Elektro-Komputer-Teknik) \\ Vol. 4, No. 2 (2020) pp. 209-218 \\ https://jurnal.politeknik-kebumen.ac.id/index.php/E-KOMTEK \\ p-ISSN : 2580-3719 \\ e-ISSN : 2622-3066
}

\title{
Aplikasi PLC Omron CP1E-N40 DT1-D sebagai Sistem Kontrol Exit Roll Kiln 1 dalam Pembuatan Keramik di PT. Satyaraya Keramindoindah
}

\author{
Arman Syaefulloh ${ }^{*}$, Ilham Akbar Darmawan ${ }^{2}$ \\ 1,2Pendidikan Vokasional Teknik Elektro, Universitas Sultan Ageng Tirtayasa, Indonesia, 42117 \\ *E-mail : ilham.ad@untirta.ac.id \\ Doi : https://doi.org/10.37339/e-komtek.v4i2.367
}

Diterbitkan oleh Politeknik Dharma Patria Kebumen

\section{Info Artikel}

Diterima :

05-11-2020

Diperbaiki :

14-12-2020

Disetujui :

14-12-2020

\begin{abstract}
ABSTRAK
Pada proses produksi keramik, keluaran pembakaran keramik (Exit Roll Kiln 1) merupakan suatu proses perubahan bentuk body dan permukaan keramik menjadi keramik yang permukaannya sudah terbentuk sesuai motif dan body nya keras. Penelitian ini bertujuan untuk mengetahui bagaimana kontrol Exit Roll Kiln 1 bekerja dalam proses pembuatan keramik. Penelitian ini merupakan penelitian case study dengan metode pengambilan data mengandalkan observasi dan pekerjaan langsung di lapangan. Hasil penelitian ini menunjukkan bahwa sistem kontrol exit roll kiln 1 memegang peranan penting dalam mengendalikan keluaran keramik secara otomatis sehingga tersusun secara rapih dan cepat sehingga menambah jumlah produksi secara efisien dalam setiap waktunya. Sistem kontrol exit roll kiln 1 keramik juga berfungsi untuk memindahkan keramik hasis percetakan hingga ke mesin penyimpanan.

Kata kunci: Exit Roll Kiln 1; PLC Omron CP1E- N40 DT1-D; Kontrol
\end{abstract}

\section{ABSTRACT}

In the ceramic production process, the output of ceramic combustion (Exit Roll Kiln 1) is a process of changing the shape of the body and the ceramic surface into a ceramic whose surface has been formed according to the motif and the hard body. This study aims to determine how the Exit Roll Kiln 1 control works in the ceramic manufacturing process. This research is a case study with data collection methods relying on observation and direct work in the field. The results of this study indicate that the roll kiln 1 exit control system plays an important role in controlling the output of ceramics automatically so that they are arranged neatly and quickly so as to increase the amount of production efficiently at any time. The ceramic kiln 1 roll exit control system also functions to move the ceramic hasis printing up to the storage machine.

Keywords: Exit Roll Kiln 1; PLC Omron CP1E- N40 DT1-D; Control
Alamat Korespondensi : Jl. Letnan Jenderal Suprapto No.73 Kebumen, Jawa Tengah, Indonesia 55431 This work is licensed under a Creative Commons Attribution-NonCommercial 4.0 International License. 


\section{PENDAHULUAN}

Pada era industri modern, sistem kontrol proses industri biasanya merujuk pada otomatisasi sistem kontrol yang digunakan [1]. Sistem kontrol industri dimana peranan manusia masih amat dominan, misalnya dalam merespon besaran-besaran proses yang diukur oleh system control tersebut dengan serangkaian langkah berupa pengaturan panel dan saklar-saklar yang relevan telah banyak digeser dan digantikan oleh system control otomatis. Sebabnya jelas mengacu pada faktor-faktor yang mempengaruhi efisiensi dan produktivitas industri itu sendiri, misalnya faktor human error dan tingkat keunggulan yang ditawarkan system control tersebut [2].

Sebagai tindak lanjut, sistem kontrol otomatis sangat diperlukan untuk pengontrolan proses kerja mesin-mesin pada industri. Jenis sistem kontrol pada industri sangat banyak dan beragam berdasarkan tingkat kecanggihan dan keakuratan sistem [3]. Salah satu sistem kontrol otomatis yang dapat digunakan adalah PLC (Programmable Logic Controller). PLC merupakan suatu bentuk khusus pengontrolan berbasis mikroprossesor yang memanfaatkan memori yang dapat diprogram untuk menyimpan intruksi-intruksi dan untuk mengimplementasikan fungsifungsi logika, sequencing, pewaktuan (timing), pencacahan (counting) dan aritmetika guna mengontrol mesin-mesin dan proses-proses dan dirancang untuk dioperasikan oleh para insinyur yang memiliki pengetahuan mengenai bahasa pemrograman [4]. PLC dapat dioptimalkan untuk melakukan tugas-tugas pengontrolan dan pengoprasian terhadap mesinmesin dan di design secara khusus sehingga tahan terhadap getaran, suhu, kelembaban dan kebisingan serta mudah diprogram. PLC dapat diandalkan karena dapat melakukan tugas-tugas pengontrolan dan pengoprasian serta di design secara khusus dan tidak memerlukan biaya yang besar untuk membentuk suatu sistem kontrol otomatis.

Pada suatu sistem kontrol otomatis tentunya di perlukan adanya komponen-komponen pendukung baik seperti hardware dan software seperti HMI (Human Machine Interface) yang digunakan dalam sebuah sistem kontrol otomatis [5]. Komponen seperti HMI sebenarnya merupakan komponen penunjang yang dapat dijadikan sebagai pelengkap dari suatu reakyasa sistem kontrol dalam dunia industri [6]. Sehingga, kelengkapan reayasa kontrol dalam sebuah sistem kontrol otomatis dapat digunakan untuk memudahkan operator dalam memonitoring sistem yang sedang beroperasi. 


\section{MATERIAL DAN METODE}

\subsection{Material}

Material dalam penelitian ini adalah objek yang menjadi sasaran observasi selama pelaksanaan penelitian. Material tersebut antara lain terdiri dari berbagai komponen yang menjadi unsur dari Mesin Exit Roll Kiln 1, yaitu: Rollers, Flag/Stopper, Motor 3 Phase, Belt Konveyor, Kurv, Counter, Encorder, Inductive Proximity Sensor, Photocell Sensor, dan HMI (Human Machine Interface).

\section{$2.2 \quad$ Metode}

Penelitian ini merupakan penelitian studi kasus yang dilakukan dalam bentuk praktik industri di PT. Satyaraya Keramindoindah. Penelitian ini dilakukan selama dua bulan, yakni sejak tanggal 1 Juli 2019-31 Agustus 2019. Pengambilan data dilakukan dengan cara observasi langsung dan wawancara [7]. Observasi dilakukan terhadadap seluruh komponen dan mesin yang terdapat di pabrik. Adapun wawancara dilakukan kepada para pegawai, supervisor dan penanggungjawab produksi. Analisis data dilakukan dengan pengumpulan data, kodifikasi dan reduksi sehingga bisa dilakukan penarikan kesimpulan untuk disampaikan secara deskriptip.

Adapun tahapan yang dilakukan pada penelitian ini dimulai dengan mengikuti prosedur yang ditetapkan dipabrik sembari melakukan pencatatan hasil observasi dan wawancara hingga proses penelitian berakhir. Temuan-temuan hasil observasi dan wawancara kemudian didiskusikan dengan ahli. Hasil diskusi tersebut selanjutnya dijadikan rujukan untuk penyusunan laporan.

\section{HASIL DAN PEMBAHASAN}

\subsection{Hasil}

Berdasarkan hasil pengamatan yang dilakukan di PT. Satyaraya Keramindoindah tepatnya di bagian Maintenance FT (Floor Tile), jenis sistem kendali otomatis yang digunakan kebanyakan PLC. Maka hasil pengamatan yang dilakukan oleh pengamat yaitu alur kerja sistem kontrol otomatis Exit Roll Kiln 1 menggunakan Programmable Logic Controller (PLC) CP1E-N40 DT1-D. Serta komponen-komponen pendukung (Hardware), dan Single Line Diagram Exit Roll Kiln 1. Bentuk fisik mesin Exit Roll Kiln 1 disajikan pada Gambar 1. 


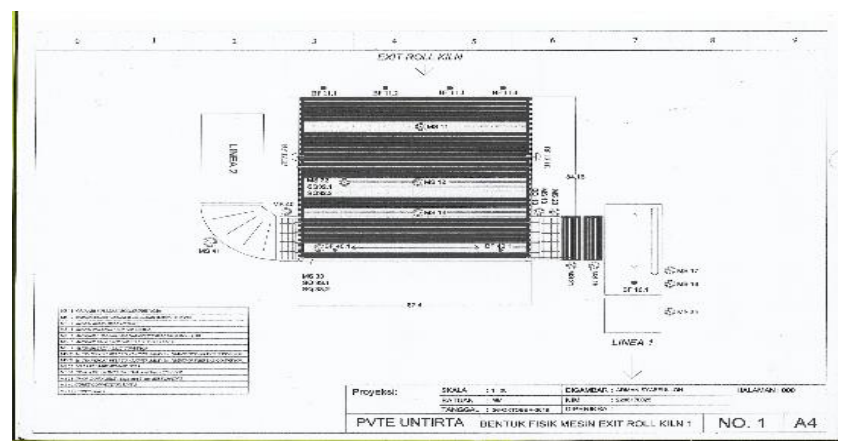

Gambar 1. Bentuk Fisik Mesin Exit Roll Kiln 1

Sumber: PT. Satyaraya Keramindoindah

\section{a. Komponen Pendukung Exit Roll Kiln 1}

\section{1) Rollers}

Pada proses pembakaran, baik masukan maupun keluaran proses pembakaran terdapat rollers yang berguna untuk membawa keramik dari pemasukan ke mesin roll kiln sampai keluaran dari mesin roll kiln. Dapat dilihat di atas rollers tersebut digerakkan oleh motor listrik, yang berfungsi untuk membawa keramik dari masukan sampai keluaran proses pembakaran keramik. Komponen rollers disajikan pada Gambar 2.

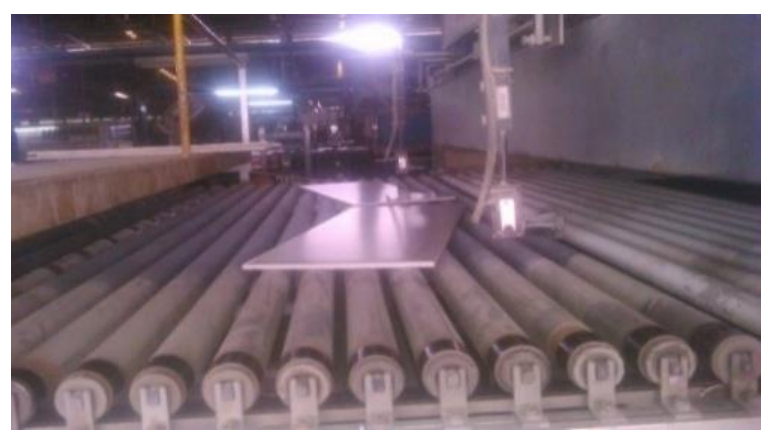

\section{Gambar 2. Rollers}

\section{2) Flag/Stopper}

Pada proses keluaran pembakaran, keramik yang kelurar dari mesin roll kiln berantakan tidak tersusun secara rapih maka pada mesin exit roll kiln terdapat flag (penghalang) yang berfungsi untuk merapihkan keluaran keramik. Flag/stopper disajikan pada Gambar 3.

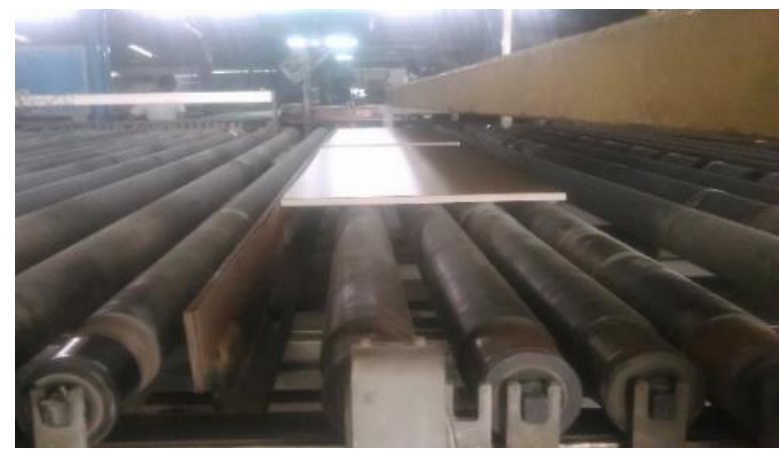

Gambar 3. Flag/Stopper 


\section{3) Motor Listrik 3 Phasa}

Pada proses masukan atau keluaran pembakaran keramik, digunakan motor listrik sebagai penggerak rollers yang membawa keramik sehingga dapat mempercepat produksi serta mengefisiensi waktu. Motor listrik yang dihubungkan pada belt kemudian rollers yang dijepit seperti roda akan menempel pada belt yang digerakan oleh motor listrik sehingga belt akan bergerak sesuai dengan instruksi on/off serta fast atau slow. Komponen motor listrik 3 phasa disajikan pada Gambar 4.

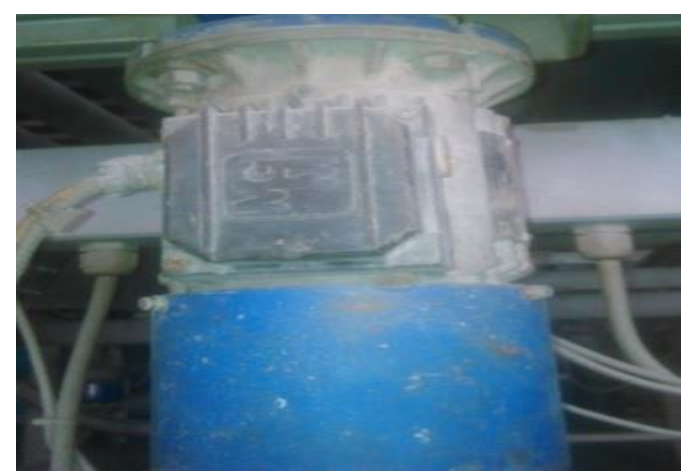

Gambar 4. Motor Listrik 3 Phasa

\section{4) Belt Konveyor}

Belt Konveyor merupakan sebuah alat untuk mengangkut yang digunakan PT. Satyaraya Keramindoindah untuk membawa keramik dari line menuju line lainnya. Dengan arah horizontal atau membentuk sudut dakian suatu sistem operasi yang lain dalam suatu proses produksi. Komponen belt konveyor disajikan pada Gambar 5.

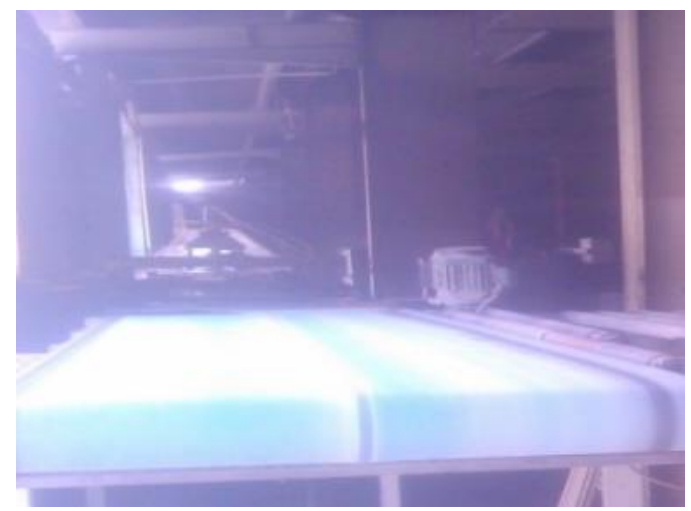

\section{5) Kurva}

\section{Gambar 5. Belt Konveyor}

Kurva merupakan sebuah alat untuk mengangkut yang digunakan PT. Satyaraya Keramindoindah untuk memutar posisi keramik $90^{\circ} \mathrm{C}$ dengan menggunakan rollers tikungan yang digerakan oleh motor listrik. Komponen kurva disajikan pada Gambar 6. 


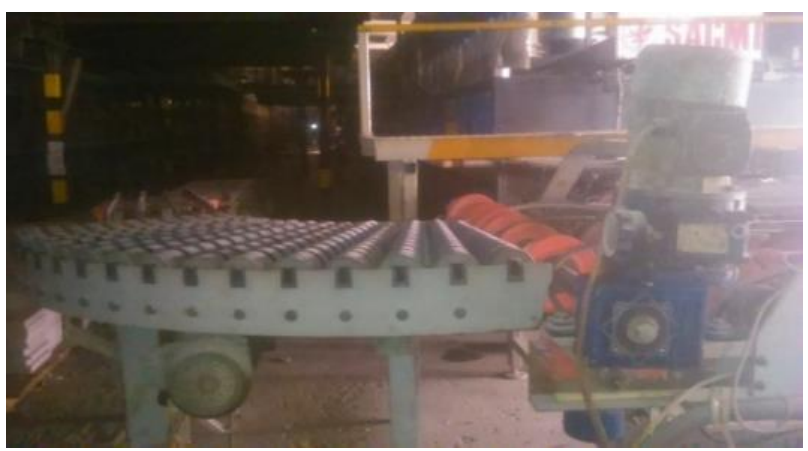

Gambar 6. Kurva

\section{6) Counter}

Counter merupakan alat yang digunakan di PT. Satyaraya Keramindoindah dalam keluaran pembakaran keramik yang berfungsi sebagai penghitung keluarnya keramik dari proses pembakaran. Counter tersebut ditampilkan dalam bentuk digital dan menempel pada panel exit roll kiln 1 untuk memudahkan operator dalam melihat jumlah keluaran keramik. Komponen counter disajikan pada Gambar 7.

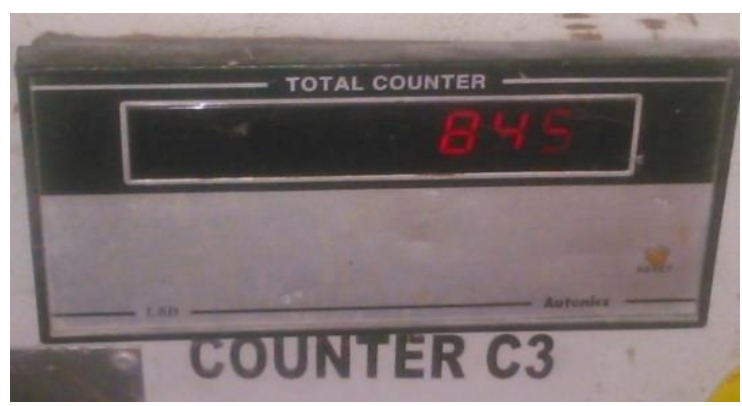

Gambar 7. Counter

\section{7) Encorder}

Encorder ini digunakan di PT. Satyaraya Keramindoindah dalam menghitung lempengan gerigi yang menatu pada as putaran motor pada belt lifting sehingga berputar dengan nilai yang diinginkan, setelah tercapai maka motor akan berhenti. Encorder disajikan pada Gambar 8.

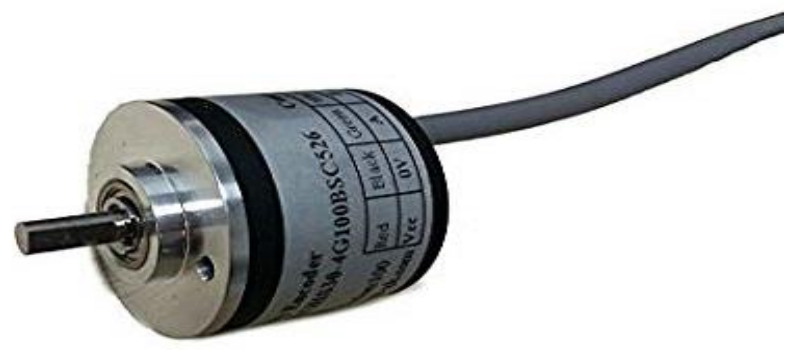

\section{8) Inductive Proximity Sensor}

\section{Gambar 8. Encorder}

Inductive proximity sensor merupakan alat yang diguanakan PT. Satyaraya Keramindoindah di mesin exit roll kiln 1, berfungsi sebagai kendali up/down flag dan belt lifting. 
Pada saat sensor membaca benda logam maka motor up/down belt dan flag akan berhenti berputar menggerakkan tuas pada posisi atas maupun bawah. Inductive Proximity Sensor disajikan pada Gambar 9.

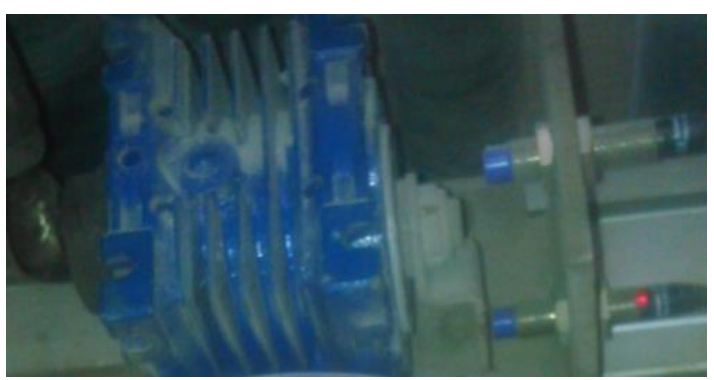

Gambar 9. Inductive Proximity Sensor

\section{9) Photocell Sensor}

Photocell sensor merupakan alat yang digunakan PT.Satyaraya Keramindoindah untuk mendeteksi keberadaan keramik menggunakan cahaya di mesin exit roll kiln, pada saat keramik menghalangi sensor maka output motor firts rollers akan berhenti dan motor up/down flag dan motor up/down belt.. akan bekerja pada posisi down secara bersamaan. Photocell Sensor disajikan pada Gambar 10.

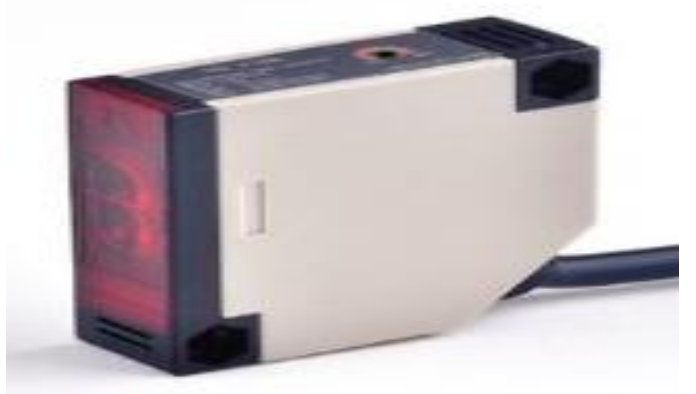

Gambar 10. Photocell Sensor

\section{0) HMI (Human Machine Interface)}

Human Machine Interface (HMI) merupakan alat yang digunakan PT. Satyaraya Keramindoindah berfungsi sebagai alat yang menghubungkan antara manusia dengan mesin di plant exit roll kiln 1 dan digunakan untuk menampilkan, mengawasi, dan mengontrol proses yang sedang berlangsung. HMI (Human Machine Interface) disajikan pada Gambar 11.

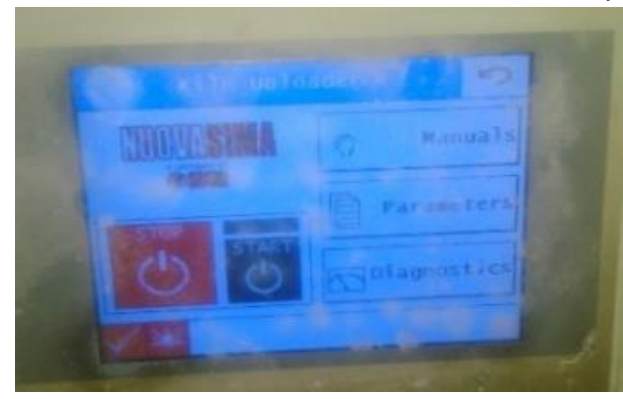

Gambar 11. HMI (Human Machine Interface) 


\subsection{Pembahasan}

Sistem operasi dilapangan mengandalkan kinerja yang presisi dari setiap komponen yang terpasang dalam sistem kendali. Sebagai upaya dalam mempermudah dalam memahami cara kerja rangkaian aplikasi photocell, inductive proximity, motor AC 3 phasa, dan inverter sebagai kontrol pada proses keluaran pembakaran keramik (Exit Roll Kiln 1) yang menggunakan PLC, maka dibuatlah blok diagram yang merupakan garis besar rangkaian tersebut. Diagram blok sistem disajikan pada Gambar 12.

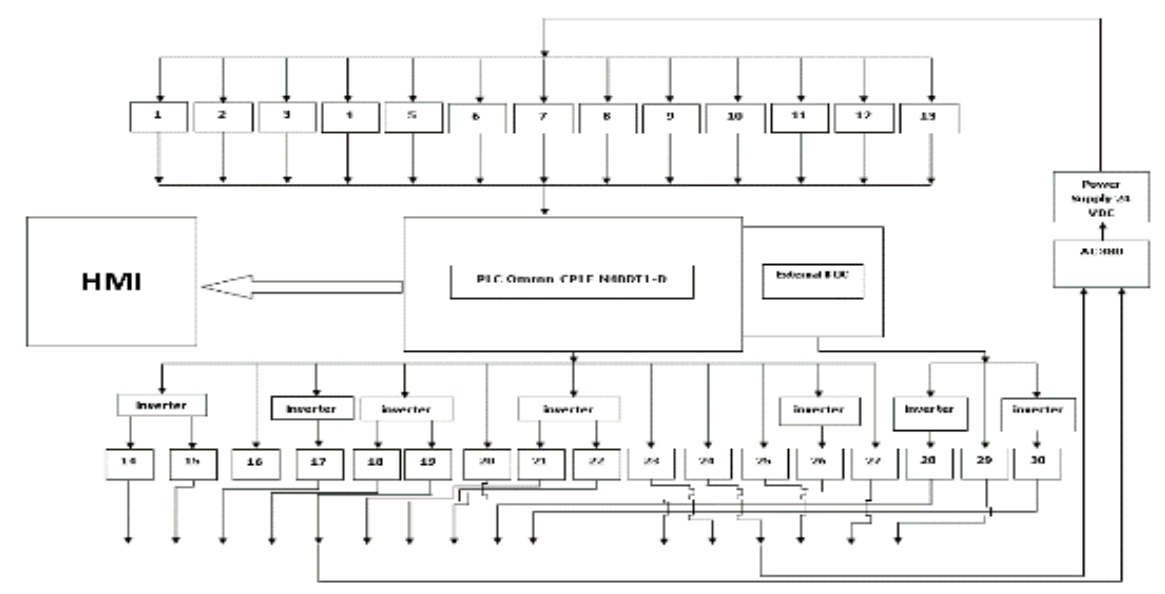

Gambar 12. Diagram Blok Sistem

Berdasarkan diagram blok tersebut, dapat diketahui bagaimana mesin keluaran keramik dari proses pembakaran bekerja. pada tahap awal, keramik dimasukkan kedalam motor first rollers. keramik mulai disusun oleh flag agar keluarannya menjadi tersusun rapi. setelah itu, keramik didrop turun untuk dimasukkan ke second roller cepat dan belt lifting naik. jika pada proses ini tidak terjadi hambatan, maka keramik akan dimasukkan ke line utama melalui motor belt conveyor, namun jika ada masalah keramik akan dimasukkan kedalam line emergnecy melalui belt conveyor lainnya. setelah proses tersebut, keramik yang berasal dari line utama akan melewati photocell counter, motor transpot to aligner belt conveyor dan dipindahkan ke motor aligner tape.

Sementara kreramik yang berasal dari line emergency akan melewati photocell counter, motor belt penghubung kurv, masuk motor tikungan dan masuk belt conveyor. selanjutnya, keramik yang datang dari motor aligner tape akan diteruskan ke penyimpanan otomatis, sementara keramik yang datang dari belt conveyor akan diangkat ke palet manual oleh operator. Proses ini tentu sangat meringkas banyak keterlibatan manusia dan secara otomatis menjadikannya lebih efisien [8]. Pengembangan otomatisasi kendali dalam industri memang 
harus mendapatkan perhatian serius untuk mendukung peningkatan produktivitas produk [1].

Proses keluaran pembakaran keramik merupakan suatu proses perubahan bentuk body dan permukaan keramik menjadi keramik yang permukaannya sudah terbentuk sesuai motif dan body nya keras. Dalam proses keluaran pembakaran keramik terdapat sebuah peralatan untuk menggerakkan atau mengontrol sebuah mekanisme atau sistem yang disebut dengan aktuator. Aktuator diaktifkan dengan menggunakan gerakan mekanis yang biasanya digerakkan oleh motor listrik, yang dikendalikan oleh sistem kontrol otomatis yang terprogram oleh Programmable Logic Controller (PLC). Komponen-komponen pendukung dalam sistem kendali exit roll kiln 1 bekerja berdasarkan program atau instruksi yang terdapat di dalam PLC sehingga mempunyai cara kerja yang berbeda-beda [1].

Pada sistem kendali exit roll kiln 1 terdapat rangkaian single line diagram dari mulai pembagian daya, rangkaian pada PLC, rangkaian pada instalasi motor listrik 3 phasa, rangkaian koneksi HMI ke PLC dan rangkaian koneksi inverter untuk mempermudah dalam memperbaiki jika terjadi kerusakan pada Hardware di mesin exit roll kiln 1. Sistem kontrol Exit Roll Kiln 1 juga terdapat rangkaian panel kontrol keseluruhan yang di bagi menjadi 4 bagian utama yaitu rangkaian pembagian daya, rangkaian I/O PLC, rangkaian instalasi motor listrik 3 phasa, dan koneksi HMI ke PLC. Rangkaian ini berfungsi untuk mempermudah dalam perbaikan jika terjadi kerusakan pada Hardware mesin Exit Roll Kiln 1.

\section{KESIMPULAN}

Berdasarkan sajian data yang telah disampaikan sebelumnya, diketahui bahwa: 1) pengendalian exit roll kiln 1 menggunakan kendali berbasi PLC yang dihubunfkan dengan HMI untuk pemberi perintah oleh user; 2) sistem kontrol exit roll kiln 1 memegang peranan penting dalam mengendalikan keluaran keramik secara otomatis sehingga tersusun secara rapih dan cepat sehingga menambah jumlah produksi secara efisien dalam setiap waktunya; 3) Sistem kontrol exit roll kiln 1 keramik juga berfungsi untuk memindahkan keramik hasis percetakan hingga ke mesin penyimpanan. 


\section{REFERENSI}

[1] W. Bolton, Programmable Logic Controller (PLC), Jakarta: Erlangga, 2003.

[2] M. W. Prabowo, "Simulasi Aplikasi Elektro Pneumatic dan PLC sebagai Kendali Pintu Air," Universitas Diponegoro, Semarang, 2012.

[3] M. C. Adib dan M. Sukmawidjaya, "Rancang Bangun Pengendalian Alat Vacuum Pressure Impregnation Berbasis PLC dan HMI untuk Gulungan Baru Mesin Listrik," Jurnal Ilmiah Teknik Elektro, vol. 14, no. 1, pp. 89-102, 2016.

[4] D. Yuhendri, "Penggunaan PLC Sebagai Pengontrol Peralatan," Journal of Electrical Technology, vol. 3, no. 3, pp. 121-128, 2018.

[5] G. W. Ilham Akbar Darmawan, "Development Skills for Growing The Society's Economy Through Technical and Vocational Education and Training Centers," Journal of Mechanical Engineering and Vocational Education (JoMEVE), vol. 1, no. 1, pp. 37-48, 2018.

[6] "Perancnagan Sistem Otomasi Proses Pelubangan Kartu Tekstil Jacquard pada Mesin Punching di PT. Buana Intan Gemilang," Jurnal Rekayasa Sistem E Industri, vol. 4, no. 1, pp. 68-75, 2017.

[7] Suharman dan H. W. Murti, "Kajian Industri 4.0 untuk Penerannya di Indonesia," Jurnal Manajemen Industri dan Logistik, vol. 3, no. 1, pp. 1-13, 2019.

[8] I. A. Darmawan, N. E. Budiyanta, D. Aribowo, M. Fatkhurokhman, M. A. Hamid, Y. Guntara dan S. Nurhaji, "Electricity course on vocational training centers: a contribution to unemployment management," Journal of Physics: Conference Series, vol. 1456, no. 1, p. 012048, 2020.

[9] N. Eka Budiyanta dan I. A. Darmawan, "Multiplatform Mobile Robot as Robotics Technology Socialization Media," International Journal of Advanced Science and Technology, vol. 29, no. 7S, pp. 3437-3444, 2020.

[10] N. E. Budiyanta, I. A. Darmawan, A. Sarah, M. Mulyadi, H. Tanudjaja dan S. Widiarto, “Line follower robot module design for increasing student comprehension in robotics," Journal of Physics: Conference Series, vol. 830, no. 1, 2020. 